\title{
Aquatic invertebrate community structure and phenology of the intermittent treed swamps of the semi-arid Paroo lowlands in Australia
}

\author{
Brian V. Timms (1D
}

Received: 29 August 2021/ Accepted: 21 October 2021/Published online: 28 October 2021

(C) The Author(s), under exclusive licence to Springer Nature B.V. 2021

\begin{abstract}
The middle Paroo lowlands in semi-arid western New South Wales support numerous intermittent wetlands of various types. Differences between them are promoted by three ecological drivers: salinity, turbidity and hydroperiod. Community structure and phenology of the two most common types, saline lakes and claypans, are known but similar ecologies are lacking for the third most common wetland, the treed swamps. These are of six subtypes distinguished by dominant tree species, geomorphology and hydroperiod, all with similar community structure and phenology, but with differing invertebrate diversities. Summed diversity is not as high as in local creek pools, the shorter hydroperiods and simpler geomorphology of the treed swamps being restrictive so that there is almost no replacement of species during the early dominance of branchiopods and later of insects. Such treed swamps are uncommon in the semi-arid zone, but much more speciose treed swamps are known under similar and seasonally dry Mediterranean climates of the Western Australian Wheatbelt where hydroperiods are more stable.
\end{abstract}

Supplementary Information The online version contains supplementary material available at https://doi.org/10.1007/ s11273-021-09846-0.

B. V. Timms $(\bowtie)$

Centre for Ecosystem Science, School of Biology, Earth and Environmental Sciences, University of New South

Wales, Kensington, NSW 2056, Australia

e-mail: brian.timms@unsw.edu.au
Keywords Branchiopod crustaceans · Insects · Diversity $\cdot$ Hydroperiod $\cdot$ Habitat heterogeneity

\section{Introduction}

Of all the intermittent wetlands of the world, most is known on those of Mediterranean lands (Boix et al. 2016) including of the two Mediterranean climate zones in Australia: southwest Western Australia and southeast South Australia- western Victoria (e.g. Bayly and Williams 1966, Davis et.al. 1993, Horwitz et al. 2009 and Pinder et al. 2004). The major environmental control in these is seasonal drying, which is shared with the dryland wetlands of the semiarid climates, though more intensely and less seasonally predictable. Adaptations to survive intermittent drying are similar in each (Williams 1985). These include resistant eggs of the branchiopod crustaceans, salinity tolerance of many crustaceans and insects, tolerance to high temperatures and good dispersal mechanisms. Introductions to Australia's arid and semiarid wetlands are provided by Davis et al. 2013, 2018 and Timms and Boulton 2001.

In the Australian semiarid zone, the middle and lower Paroo lowlands on a plainlands in north-western New South Wales contain many and varied wetlands, almost all unreliably flooded (Goodrick 1984; Timms and Boulton 2001) (Fig. 1). All occur in hollows due 


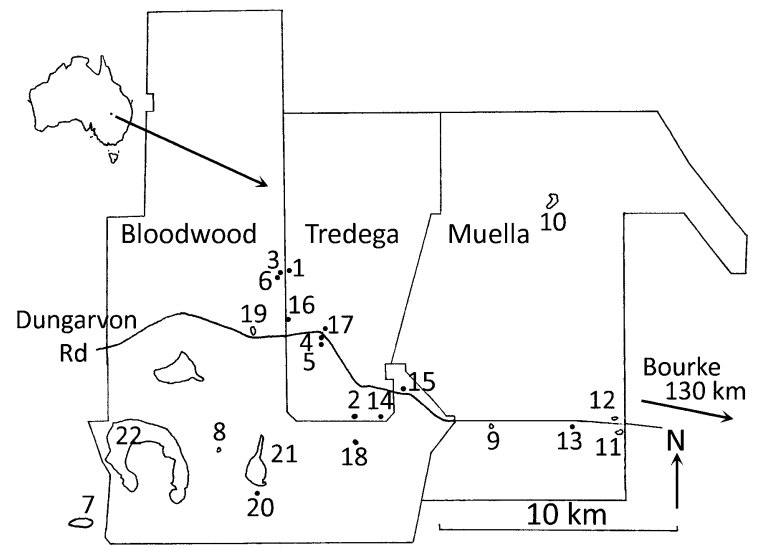

Fig. 1 Map of Bloodwood, Tredega and Muella Stations showing locations of the 18 treed swamps and four other sites. Code to wetlands (all names unofficial except 21, 22 and used only locally): 1. Fence, 2. Far Homestead, 3. False Goat, 4. Reedy. 5. Washout, 6. Real Goat, 7. Utah, 8. George, 9. Donkey, 10. Carters, 11. Muella East South, 12. Muella East North, 13. Lismore, 14. Near Homestead, 15. Boggy Bend, 16. Quandong, 17. Tredega T/O, 18. Marsilea, 19. Ski Lake, 20. Turkey claypan, 21. Gidgee salt lake, 22. Horseshoe salt lake

either to dunes blocking drainage lines, or to localised deflation. An exception, not considered here, are the riverine waterholes due to evorsion by water currents and containing water permanently.

The intermittent wetlands of this region are filled either by riverine floodwater or from local rainfall. Both types can support trees. Prominant among the former are lignum swamps (Muehlenbeckia cunninghamii) and Yapunyah (Eucalyptus ochrophloia) tree swamps. These are inundated for many months following a flood and have a distinctive invertebrate fauna including crabs and decapod shrimps (Timms 1997a) but are not included here. This paper focuses on the wetlands filled entirely from local rainfall which includes saline lakes (large and with bare surfaces, or small and with samphires (Arthrocnemum spp.), innumerable shallow claypans, many varieties of vegetated swamps and marshes, and a few temporary creek pools, small grassy pools, and shallow flood outs. The ecological drivers characterising these wetlands are salinity, turbidity and hydrology (Timms and Boulton 2001). For the treed swamps, other drivers may be associated with the trees, swamp structure affecting invertebrate diversity, changes in the water as it ages, and phenology.

Those wetlands filled by local rainfall have a distinctive variable hydrology and fauna. Gafney's
(1975) variability index $(90 \%$ percentile $-10 \%$ percentile divided by the $50 \%$ percentile of annual rainfall) is close to 1.50 for the area, which is not far from the extreme value of 1.75 for Australia. Of the aquatic fauna of the area, only the fauna of the saline lakes have been sufficiently studied to claim it is an inland one distinct from those of various groups of southern lakes (Timms 2007). The anostracan fauna is of eastern Australian character (Rogers and Timms 2014) and, judging from their listings in many regional studies, most of the inland insects are widespread across the continent.

The characteristics of many of these wetlands have now been elucidated. Foremost are the saline lakes (Timms 1993, 1998a, 2018), followed by claypans (Hancock and Timms 2002; Timms 2002), creek pools (Timms 2001), with less known of the large episodic terminal lakes, smaller intermittent freshwater lakes and permanent riverine waterholes (Timms and Boulton 2001). Least is known of the fauna, phenology and ecological drivers of the vegetated temporary swamps surrounded by trees and supporting a few trees within. This paper considers these, the last of the major Paroo wetlands to be studied.

The trees in these Paroo wetlands are probably not integral to their ecology. Certainly they are the most obvious feature seen from near and afar, but they are largely peripheral and their bases are only inundated when such a swamp is first flooded. They probably supply some leaf litter and more noticeably woody detritus which may add to invertebrate diversity (see later) and also perhaps shade the littoral from the fierce summer sun. Locally there are two dominant tree species, leading to apparently different wetland types: Black Box (Eucalyptus largiflorens) swamps and Poplar Box (E. populnea) flats. The Black Box swamps occur almost exclusively in the dune fields and the Poplar Black Box flats mainly in the red earth country; also Black Box swamps tend to be smaller and deeper than Poplar Box flats and with a longer hydroperiod maybe 4-6 months versus 2-5 months, but there are some exceptions. Both wetland types may have internal channels, a feature of some aridzone wetlands (Tooth and McCarthy 2007), but only Black Box swamps have uneven deposits of ex-terrestrial soils deposited during major inflows. Black Box trees also occur as tree cover in some lignum swamps, and in drainage lines across a wide 
area of the southern and central eastern inland (Cunningham et al. 1981).

Treed swamps in drylands are uncommon across the world with most apparently being in Australia and then being concentrated in the Middle Paroo catchment of northwestern New South Wales. In addition, the mediterranean zone of Western Australia has a few different types of wetlands dominated by trees, each with a different diversity of invertebrates, some halotolerant. Trees include Swamp Yate (E. occidentalis), and Melaleuca spp. Another concentration of treed swamps occurs in the sahel of Senegal, Africa (Lahr et al. 1999).

The purpose of this paper is to investigate of the basic ecological character of these treed swamps, one of the major dryland wetland types of the middle Paroo. In a comprehensive study of Paroo wetlands, they were left to last because of the difficulty in sampling soft and retreating shorelines and the perceived need to operate in a major flooding which occurs only occasionally. Besides characterising their flooding regime, variations in their conductivity, $\mathrm{pH}$ and turbidity were monitored. It is assumed their fresh waters are dominated by $\mathrm{Na}$ and $\mathrm{Cl}$ ions, as are almost all waters in the Paroo (Timms 1993). Invertebrate species diversity is an important discriminator between Paroo wetlands not only between major types but perhaps between subtypes as suspected among the treed swamps. So many questions arise, including 1. Are their distinctions between the subtypes? and 2 . Are the ecological drivers in these temporary freshwater wetlands similar to most Australian arid-zone wetlands (Davis et al. 2018) and indeed the wider aridzone or can they be explained within those already known for other Paroo wetlands, i.e. salinity, turbidity and hydrology?

\section{Study site and methods}

The study area lies on three adjacent properties, Bloodwood, Tredega and Muella Stations, $130 \mathrm{~km}$ northwest of Bourke in western New South Wales and $50 \mathrm{~km}$ east of the Paroo floodplain. The study area is $250 \mathrm{~km}^{2}$ and consists of two types of countryundulating low ridges on sedimentary and silcrete rocks covered by red earth soils to the east and dunefields of deep siliceous sands to the west (Hazelton and Johnson 1973).
Mean annual rainfall is $307 \mathrm{~mm}$ at Dungarvon Station immediately to their west (recorded by D. Leigo 1966 to 2016). Rainfall is maximal in summer (mean $98 \mathrm{~mm}$ ) and minimal in winter (mean $60 \mathrm{~mm}$ ) (C. Sives, pers. com.), with occasional large falls (e.g. $261 \mathrm{~mm}$ over two days in March 2021) and long droughts. Although there is some seasonality in the averages, the reality is rainfall is highly variable from month to month, and year to year. Evaporation is more reliable averaging about $3000 \mathrm{~mm}$ per year for this area (Warner 1977). What seems an anomaly, the amount of water in the bigger lakes is often maximal in winter and minimal in spring (C. Sives, pers.com) but this is due the overriding influence of seasonal variation in evaporation. Typically smaller wetlands studied here fill in mid to late summer and are dry again by winter or spring, but there exceptional years.

This study is based mainly on a major fill on March $3-5,2020$ resulting from $261 \mathrm{~mm}$ rainfall and very little afterwards. Eighteen treed swamps on three adjacent stations, Bloodwood, Tredega and Muella in the Middle Paroo were chosen and subsequently monitored monthly for six months (March 19-23; May 5-7; July 3-5; August 1-3; September, 6-8; but missed in June due to covid-19 travel restrictions (Figs. 1, 2). Also some data were collected from the same sites in more average flooding in May 2019, but it could only be followed for 6 weeks at fortnightly intervals. Also, comparative collections were taken from a nearby claypan, a freshwater lake and two saline lakes on Bloodwood. The treed swamps were grouped into six categories with an aim of three in each. The first criterion was the tree species present, and the second whether or not channels were present, and the third was size ( $>$ or $<0.5$ ha), all factors which may be additional ecological drivers. Comments on overall filling frequency are based on field experience 1987-2021 inclusive.

In the main study, water samples from the 22 sites were collected regularly and conductivity measured with an Oakton ECTestr11 meter, $\mathrm{pH}$ with a Hanna pHep meter and turbidity with a Secchi disc tube. Maximal inundated area of each site was estimated from Google Earth maps by comparing ground extent in March 2021 with features visible on their 2015 image. Note that inundated areas vary with each fill as not one of the swamps overflow, but the levels of March 2021 were near maximal seen during 1987-2021. Depths were determined by a dumpy 

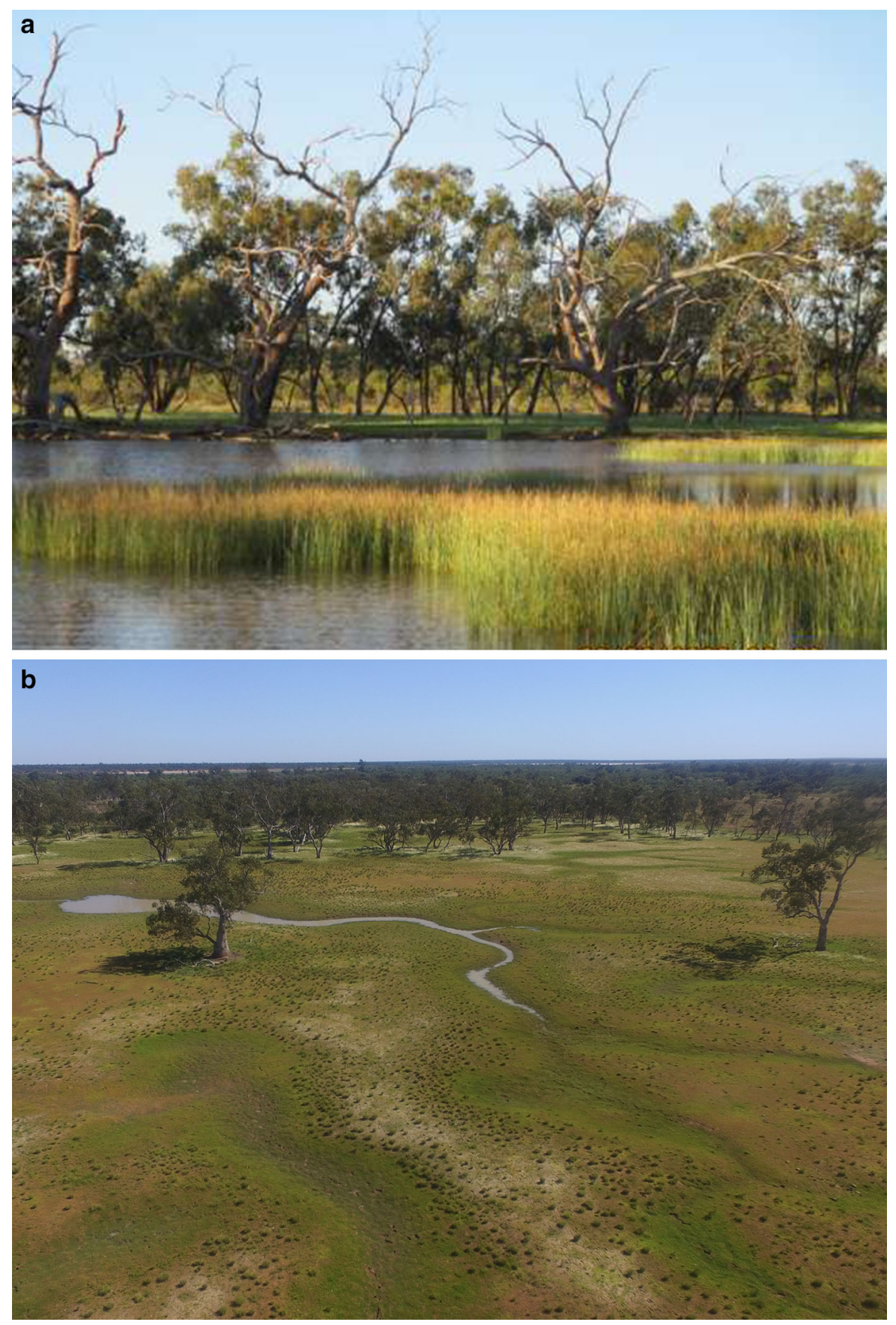

Fig. 2 a Reedy Black Box swamp showing the typical ring of trees around the swamp and often inundated on initial flooding. The dead trees relate back to an extended flooding when they

level from the vertical height of a marker installed at full level in March and the deepest place when the swamps dried. Habitat heterogeneity was subjectively measured equally by extent of bottom irregularity died due to excessive water. b Utah poplar box flat showing an extensive plain with a few trees but many at the far edge and a channel within the wetland

determined as three values-low, medium, high, the area estimated to be vegetated during the inundation period, again recorded as one of three values-low, medium, high, and the amount of inundated woody 
detritus across the floor of the swamp as counted when the site was dry, again as three values-low, medium, high. The result was a simple index ranging from 1 to 9, not detailed, but of sufficient robustness for purpose. Physicochemical measurements are summarised in SM1.

All biological sampling was done from the swamp edge, as it was dangerous to wander too far out due to unpredictable location of unconsolidated wetted sediments. So, while every effort was made to make the samples representative, this was not strictly possible, i.e. all samples were taken from different physical sites as each swamp dried. Zooplankton was collected with a net of $159 \mu \mathrm{m}$ mesh and opening $25 \times 15 \mathrm{~cm}$ and trawled for $2 \mathrm{~min}$ in each swamp on each visit. Littoral invertebrates were collected with a D-shaped pond net $(25 \times 23 \mathrm{~cm})$ of mesh $1 \mathrm{~mm}$ trawled for $10 \mathrm{~min}$ altogether at 3 different sites in each swamp on each visit. The zooplankton collection was preserved in total in alcohol, but the littoral invertebrates were sorted in a tray and only representatives of each species retained in alcohol. Abundances of both zooplankters and littoral invertebrates were estimated on a $\log$ scale $(1-2$ individuals $=0.1 ; 3-5=0.3$; $6-8=0.7 ; 9-20=1 ; 21-50=1.3$, etc.). These estimations were quick and of sufficient robustness for the multivariate analysis.

Three levels of diversity were used: alpha diversity is simply the number of species instantaneous present on each collecting occasion averaged over each site within the six groups; beta diversity is the change in species diversity from one month to the next at each site; and gamma diversity is the total number of species encountered at each site through the study period.

The Pearson Correlation Coefficient in Excel was used to test a possible relationship between alpha diversity and both hydroperiod and habitat heterogeneity. It was assumed the data were linear. To test questions of faunal relationships between the six groups of swamps and flats, multivariate analyses were calculated using PRIMER (v5) (Clarke and Gorley 2001). Field and laboratory counts were already $\log$ transformed and a similarity matrix constructed based on the Bray-Curtis similarity coefficient. Non-metric multidimensional scaling (NMDS) using 999 permutations was then performed to visualise patterns in assemblage composition among the data sets. Data collected over the same time period on a nearby freshwater lake, a claypan and two saline lakes of widely different salinity ranges were added to ascertain their relationships to the treed swamps and flats.

\section{Results}

The treed sites, all ephemeral, varied greatly in size with the Poplar Box Flats generally larger than the Black Box swamps (Table 1). This is an artefact as all the large Black Box swamps on Bloodwood Station have been modified to hold permanent water for stock and hence not part of the study. Poplar Box flats generally were almost flat in profile, but sometimes with a distinctly deeper channel accounting for much ( $>60 \%$ ) of their recorded maximum depth, whereas the Black Box swamps typically were saucer shape, often again with a distinct channel but contributing less $(<40 \%)$ to their maximum depth. In the swamps and flats studied, those with channels were larger than those without (Table 1). In Black Box swamps a further irregularity was provided by randomly arranged humps of unstructured sediments, thought to be due to deltaic sedimentation in the past. In the March 2021 flooding, a new delta formed in the Washout Swamp. Particularly small sites of both types were considered separately as their hydroperiods were distinctly shorter (Table 1).

Water in all sites was fresh $(<250 \mu \mathrm{S} / \mathrm{cm})$, with the larger, deeper swamps and flats concentrating more over time than the smaller or shallower sites (Table 1, SI 1). Also, $\mathrm{pH}$ varied though the hydroperiod, commencing about neutral and moving quickly to being moderately alkaline (i.e. ca 7.0 to ca. 8.3) (Table 1, SM 1). Water turbidities were low, always below 70 NTU and often < 30 NTU (Table 1, SM 1). The Black Box Swamps cleared somewhat during their hydroperiod, but the Poplar Box Flats increased in turbidity with time (Table 1). This is not natural as stock had access to the Poplar Box Flats on Muella Station but not the others.

Eightytwo taxa of invertebrates were encountered overall (SI 2), though 25 of these were collected fewer than three times. Few were unique to any one site or type of site, though Eulimnadia hansoni, Eocyzicus phytophyllus, Asplanchna spp. and Laninularia racemovata were restricted to Poplar Box flats. Black Box sites with channels were the most speciose, 
Table 1 Physicochemical features of six types of treed swamps on Bloodwood and Muella Stations

\begin{tabular}{|c|c|c|c|c|c|c|}
\hline Sites & No. & $\begin{array}{l}\text { Mean } \pm \text { SE } \\
\text { area (ha) }\end{array}$ & $\begin{array}{l}\text { Mean } \pm \text { SE maximum } \\
\text { depths }(\mathrm{cm})\end{array}$ & $\begin{array}{l}\text { Mean cond first- } \\
\text { final }(\mu \mathrm{S} / \mathrm{cm})\end{array}$ & $\begin{array}{l}\text { Mean } \mathrm{pH} \\
\text { first-final }\end{array}$ & $\begin{array}{l}\text { Mean turbidity first- } \\
\text { final (NTU) }\end{array}$ \\
\hline $\begin{array}{l}\text { Black box swamp } \\
\text { with channels }\end{array}$ & 3 & $2.7 \pm 0.4$ & $90.0 \pm 9.8$ & $57-250$ & $7.1-8.7$ & $22-5$ \\
\hline $\begin{array}{l}\text { Black box swamps no } \\
\text { channels }\end{array}$ & 3 & $1.2 \pm 0.2$ & $74.3 \pm 14.2$ & $73-173$ & $7.1-8.2$ & $34-14$ \\
\hline $\begin{array}{l}\text { Black box swamps } \\
\text { small }\end{array}$ & 2 & $0.3 \pm 0.1$ & $28.5 \pm 3.5$ & $55-70$ & $6.8-8.4$ & $25-10$ \\
\hline $\begin{array}{l}\text { Poplar box flats with } \\
\text { channels }\end{array}$ & 3 & $7.1 \pm 2.1$ & $64.7 \pm 11.2$ & $32-77$ & $7.4-8.3$ & $45-58$ \\
\hline $\begin{array}{l}\text { Poplar box flats no } \\
\text { channels }\end{array}$ & 4 & $6.3 \pm 4.8$ & $26.7 \pm 4.3$ & $35-95$ & $7.0-8.4$ & $39-68$ \\
\hline $\begin{array}{l}\text { Poplar box flats } \\
\text { small }^{\mathrm{a}}\end{array}$ & 3 & $0.3 \pm 0.1$ & $23.8 \pm 6.0$ & 73 & 7.2 & 10 \\
\hline
\end{tabular}

${ }^{\mathrm{a}}$ These sites had water only once, therefore there is only one value for each

followed by Poplar Box flats with channels, then Black Box sites without channels, Poplar Box sites without channels and the short hydroperiod sites last (Table 2). The channels add to habitat complexity and hence species diversity. This contrast in diversity patterns was evident also temporal patterns in momentary alpha diversity between the deepest sites with channels in which diversity increased with time and the shallowest nearly flat Poplar Box sites without channels in which diversity slowly decreased as they became shallower (Fig. 3a, b). Alpha diversity was significantly higher the longer the hydroperiod $\left(\mathrm{r}^{2}=0.7921, \mathrm{P}<0.01\right)$ and also was significantly influenced by habitat heterogeneity $\left(\mathrm{r}^{2}=0.7583\right.$, $\mathrm{P}<0.01)$. Gamma diversities were also higher the longer the hydroperiod, but these were not tested statistically. Beta diversities indicated considerable changes between months for all sites. While this is influenced for the phenological change over between early dominance by large branchiopods to that by insects (see below), some is explained by rarity of many species and hence missing a record in some months.

There was a major change in communities with aging of sites (Table 4), with all sites dominated initially by large branchiopods then insects and changing slightly as species matured according to their life cycle characteristics. Zooplankton usually was dominated early and briefly by Moina australiensis then communities were dominated by either or both Boeckella triarticulata and Daphnia carinata s.l. Larger littoral invertebrates were sparse initially though Triops australiensis, larger clam shrimps (Limnadopsis birchii, L. tatei and L. parvispinus) soon

Table 2 Diversity in six types of treed swamps on Bloodwood and Muella Stations

\begin{tabular}{lllll}
\hline Sites & Number & Alpha diversity mean \pm SE & Beta diversity mean \pm SE & Gamma diversity \\
\hline Black box swamps with channels & 3 & $27.7 \pm 1.3$ & $18.3 \pm 1.97$ & 54 \\
Black box swamps no channels & 3 & $19.4 \pm 0.7$ & $14.0 \pm 1.14$ & 49 \\
Black box swamps small & 2 & $16.0 \pm 0.9$ & $18.5 \pm 2.35$ & 32 \\
Poplar box flats with channels & 3 & $21.9 \pm 1.4$ & $18.6 \pm 2.11$ & 44 \\
Poplar box flats no channels & 4 & $14.1 \pm 0.7$ & $16.4 \pm 2.94$ & 40 \\
Poplar box flats very small & 3 & $6.3 \pm 0.3$ & (a) & 13
\end{tabular}

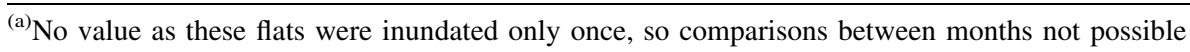


a

35

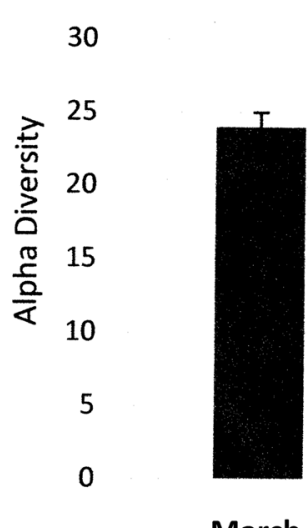

b 18

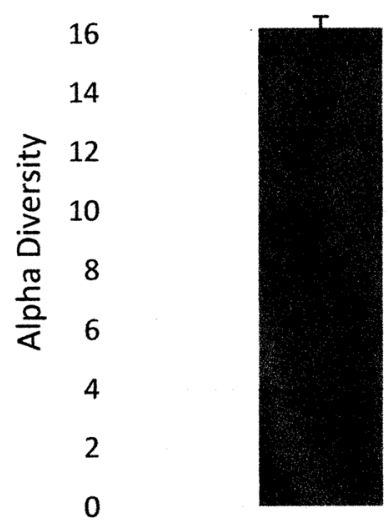

March

Black Box Swamps with channels

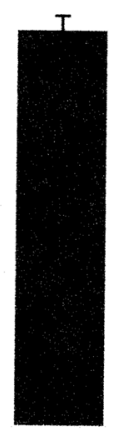

May

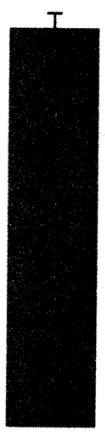

July

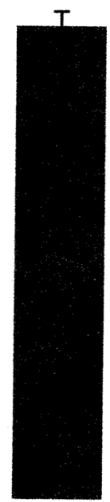

August

Poplar Box Flats no channels

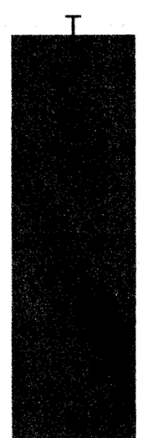

May

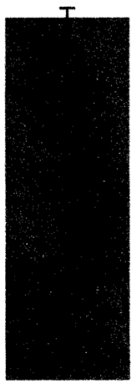

July
Fig. 3 a Alpha diversity of invertebrates in the three Black Box swamps with channels on Bloodwood station, northwestern New South Wales over the six month study period, March to August, 2020. The error bars represent one standard error.

were obvious as well as Micronecta sp. After two months these had largely disappeared to be replaced by various juvenile insects. These matured over the ensuing months, with almost no addition or replacement of species. Both the larger invertebrates and smaller planktonic invertebrates had many species considered uncommon (noted as u in SM 2) or in low numbers and not always present in one particular site or group of similar sites (marked as x in SM 2). In the main study of 2020, most branchiopods were restricted to the first sampling soon after filling and were not present at 2 months, but in 2019, when the sampling frequency was fortnightly, many persisted for b Alpha diversity of invertebrates in the four Poplar Box flats without channels on Bloodwood and Muella stations, northwestern New South Wales over the 5 month study period, March to July, 2020. The error bars represent one standard error

6 weeks. Ozestheria packardi sensu lato was unusual for a branchiopod, persisting right through the hydroperiod in some sites.

No data were collected on diets of the invertebrates, though from generalised information, most initial branchiopod colonizers were filter feeders on algae, and were replaced by more filter feeders in the form of copepods and cladocerans. Ostracods also ate algae, but by scraping or collecting them from plants and sediments. Triops was an early omnivore in most sites and Eretes larvae a prominent early carnivore in some sites. Interestingly their presence was patchy, varying in different fills (in some sites the 2019 populations 
were different from those in 2020). Detritus and partial ominivorous feeders were represented by Micronecta, Agraptocorixa and various beetle adults. Prominent carnivores towards drying were Anisops spp. and odonates. Strict vegetarians were uncommon, represented by limited and patchy populations of snails, though the periphyton on the plants (mainly Chara, also Myriophyllum) supported Cloeon, many ostracods and Micronecta.

An ordination of the 18 ephemeral treed swamps plus an episodic freshwater lake, a claypan, and two saline lakes as outgroups, is shown in Fig. 4. The dominant invertebrates are listed in Table 3. It suggests a close relationship between the three channelled Black Box Swamps, the three non-channelled Black Box Swamps, the three channelled Poplar Box Flats and the four non-channelled Poplar Box Flats. Thus, these four wetland types can be considered as one, the treed swamps. The smaller Black Box swamps are not far removed from this cluster, with the four small Poplar Box flats further removed. As far as is known, all species are widely distributed right across the inland, though a few branchiopods are restricted to the mid-eastern parts.

\section{Discussion}

This study is focused on the ecological characters that separate treed swamps from other wetland types in the middle Paroo lowlands. The physicochemical milieu and invertebrates of the saline lakes, claypans and creek pools have already been elucidated in some detail and some information is available on wetlands of lessor importance (Timms and Boulton 2001). Few other dryland wetland systems have such an array of wetland types and although invertebrate diversity is not remarkable in any one particular type, when considered together it is impressive, particularly for large branchiopods (eg. Timms 2015; Schwentner et al. 2015). Moreover besides the major environmental differences between wetland types, minor variations in habitat complexity contribute to invertebrate diversity, as explored in these treed swamps. This is a subject of many examples both in sets of wetlands in remote drylands (e.g. Hancock and Timms 2002; Timms 1998b) as well as in more accessable Mediteranean wetlands (e.g. Boix et al. 2016; Florencio et al. 2014a).

Over 34 years of casual monitoring at Bloodwood, the 2020 flooding was the greatest ever observed since white settlement, while the 2019 filling, though not measured, was more 'average' at about half the

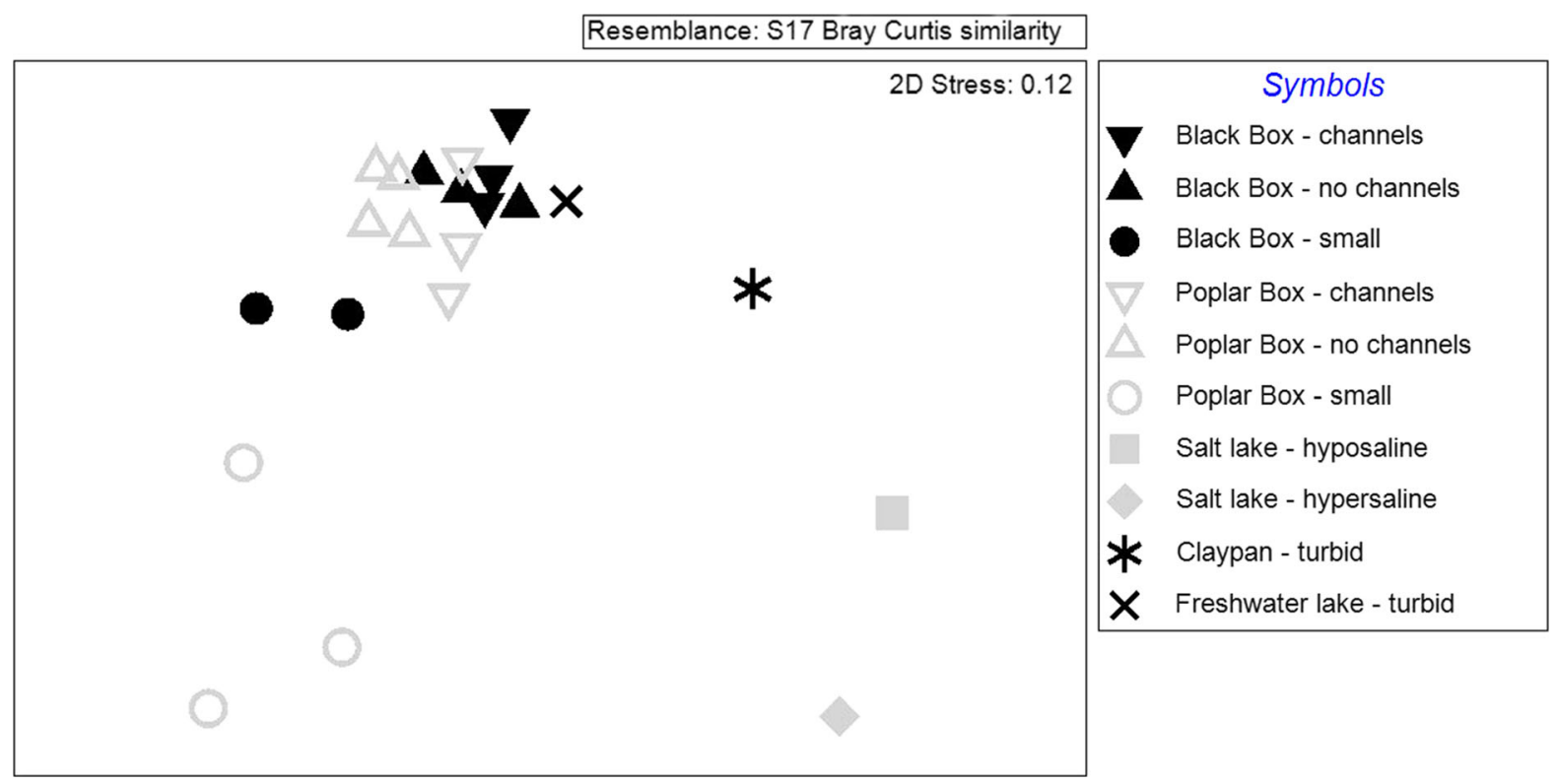

Fig. 4 Ordination of the 18 treed swamp plus a freshwater lake, a claypan and two salt lakes on Bloodwood, Tredega and Muella stations 
Table 3 Phenology of dominant invertebrates in treed swamps on Bloodwood and Muella

\begin{tabular}{|c|c|c|}
\hline Two weeks & Two months & Four to six months \\
\hline \multicolumn{3}{|l|}{ A. Poplar box flats } \\
\hline \multicolumn{3}{|l|}{ Open waters } \\
\hline Moina australiensis & A cyclopoid & A cyclopoid \\
\hline Branchinella spp. & Daphnia carinata & rotifers \\
\hline \multicolumn{3}{|l|}{ Paralimnadia or Eulimnadia } \\
\hline \multicolumn{3}{|l|}{ Littoral } \\
\hline Micronecta sp. & Anisops spp. juv. & Anisops spp. adults \\
\hline Agraptocorixa juv. & Agraptocorixa adults & mature Odonata \\
\hline Triops australiensis & Odonata juv. & \\
\hline Berosus larvae & adult dytiscids & \\
\hline \multicolumn{3}{|l|}{ Eretes larvae } \\
\hline \multicolumn{3}{|l|}{ Sternopriscus adults } \\
\hline \multicolumn{3}{|l|}{ Cloeon larvae } \\
\hline \multicolumn{3}{|l|}{ A mosquito } \\
\hline \multicolumn{3}{|l|}{ A. Black box swamps } \\
\hline \multicolumn{3}{|l|}{ Open waters } \\
\hline Moina australiensis & Boeckella triarticulata & Boeckella triarticulata \\
\hline Branchinella spp. & Daphnia carinata & Calamoecia lucasi \\
\hline Limnadopsis spp. & various ostracods & Daphnia carinata \\
\hline Paralimnadia queenslandicus & Ozestheria 'packardi' & \\
\hline Ozestheria spp. & & \\
\hline \multicolumn{3}{|l|}{ Littoral } \\
\hline Triops australiensis & Anisops juv. & Anisops adults \\
\hline Micronecta sp. & Agraptocorixa juv. & Agraptocorixa adults \\
\hline Clam shrimps as above & Cloeon larvae & mature Cloeon larvae \\
\hline Eretes larvae & Triplectides larvae & mature Triplectides larvae \\
\hline Berosus larvae & dytiscid adults & chironomid larvae \\
\hline Sternopriscus adults & Odonata juv. & Mature Odonata \\
\hline
\end{tabular}

inundated area measured in 2020. The great flooding of 2020 was akin to that in 1974-1976 (D. Leigo, pers. com.) and going back in the wider Paroo to 1885 of great floodings of Lake Wyara in 1890, 1959-1950 and 1974-1976 (A. McGrath pers. com; Timms 1998b) indicate a return interval for remarkable flooding rains of about 45-50 years.

In inland eastern Australia a major climate driver is the El-Nino - La Nina system of the Pacific Ocean. La Nina years are wetter and cooler and presently occur on a 10-11 year cycle (BOM 2021). Larger dryland lakes such as Lake Wyara in the southern Queensland Paroo flood and dry cyclically approximately every 10 years, the correlation coefficient between the Southern Oscillation Index and full and dry periods $1887-1994$ is highly significant $(r=0.622, \mathrm{n}=34)$
(Bridgman and Timms 2012). Such a dominant driver also affects the treed swamps.

In general, Black Box swamps flood every 2-3 years, always in a La Nina climatic year and perhaps weakly two or rarely three times in between or two years in succession if La Nina events last two years. Smaller black box swamps such as Marsilea swamp floods to a maximum ca $30 \mathrm{~cm}$ depth only in La Nina years, with other wettings $5-10 \mathrm{~cm}$ deep and lasting only a few days to weeks. Poplar Box flats flood less frequently at about 3-5 year intervals, again in the same temporal pattern. In strong El Nino years, all swamps remain dry for years, perhaps up to 6 years, as in the Millennium drought of 2001-2006.

There are vast differences in habitat characteristics and faunal composition between these treed swamps 
and salt lakes and claypans, the other common wetlands of the Paroo (Fig. 4, Table 4; Timms and Boulton 2001). The salt lakes are most different: their saline waters have entirely different invertebrates including the ostracods Diacypris spp., Mytilocypris splendida and Trigonocypris globulosa, the cladocercan Daphniopsis queenslandensis and the anostracan Parartemia minuta (Timms 1993, 2018) Claypans share some features with the treed swamps, mainly some insects and Triops australiensis, but their high turbidity is suitable for a range of branchiopods, such as Branchinella affinis, B. budjiti, B. lyrifera and $B$. occidentalis as well as spinicaudatans Ozestheria spp. and Eocyzicus argillaquus (Hancock and Timms 2002). On the other hand, there are many similarities in habitat and fauna between these treed swamps and episodic freshwater lakes and creek pools (Fig. 3, Table 4; Timms and Boulton 2001). Paroo treed swamps are not as speciose as local freshwater lakes (Timms and Boulton 2001) and creek pools (Timms 2001), though the majority of invertebrates listed for the treed swamps also occur in the freshwater lakes and creek pools. The ecological drivers suggested for all Paroo wetlands also apply specifically to these treed swamps, namely water fresh $(\mathrm{EC}<250 \mu \mathrm{S} / \mathrm{cm})$ (as against saline waters of the salt lakes and samphire lakes), water turbidity low ( $<50 \mathrm{NTU}$ ) (as against high turbidity in claypans and crystal-clear saline waters and somewhat turbid waters of other fresh waters), and relatively short hydroperiods ( $<6$ months) (applies to many Paroo habitat types but some are permanent or episodic persisting a year or more).

In those treed wetlands with channels and the longest hydroperiods there is an increase in diversity with time and in all others a decrease (Figs. 3a, b). Similar trends have also been noticed in the Doñana wetlands with longer hydroperiods in Spain (Florencio et al. 2011), but local claypans exhibit a marked decrease in diversity with wetland wetting aging (Timms 2002). Explanations vary, but in the channelled tree swamps there may be addition of species from other drying wetlands to a habitat resource still available in the channels, or to more efficient collecting in the easier field conditions. For the simpler tree swamps or flats without channels, and the claypans, the less heterogenous environment as the wetland dries is a likely explanation.

Among the treed swamps and flats, it seems the trees themselves are not important in their ecology throughout a filling-drying cycle. Only in some floodings are the peripheral tree bases flooded, but when they do, some evidence suggests diversity is enhanced. This was seen occasionally by increased

Table 4 Prominent invertebrates in five wetland types in the Paroo

\begin{tabular}{|c|c|c|c|c|}
\hline Treed swamps ${ }^{\mathrm{a}}$ & Salt lakes ${ }^{\mathrm{b}}$ & Claypans $^{\mathrm{c}}$ & Episodic freshwaters $^{\mathrm{d}}$ & Creek pools $^{\mathrm{e}}$ \\
\hline $\begin{array}{l}\text { Branchinella } \\
\text { frondosa }\end{array}$ & Parartemia minuta & $\begin{array}{l}\text { Branchinella } \\
\quad \text { lyrifera }\end{array}$ & $\begin{array}{l}\text { Branchinella } \\
\text { australiensis }\end{array}$ & $\begin{array}{l}\text { Branchinella } \\
\text { australiensis }\end{array}$ \\
\hline Limnadopsis spp. & $\begin{array}{l}\text { Daphniopsis } \\
\text { queenslandicus }\end{array}$ & Branchinella affinis & Paralimnadia spp. & Limnadopsis spp. \\
\hline $\begin{array}{l}\text { Boeckella } \\
\quad \text { triarticulata }\end{array}$ & Trigonocypris globulosus & Ozestheria lutraria & Ozestheria parkardi & Boeckella triarticulata \\
\hline Daphnia carinata & Cyprinotus edwardsi & Ozestheria packardi & Boeckella triarticulata & Ozestheria packardi \\
\hline Micronecta sp. & Diacypris spp. & Micronecta sp. & Daphnia carinata & Micronecta sp. \\
\hline Anisops spp. & Micronecta sp. & Anisops stali & Anisops spp. & Anisops spp. \\
\hline Odonates & Anisops spp. & Eretes australis & Dytiscid beetles & Dystiscid beetles \\
\hline Dytiscid beetles & Tanytarsus barbitarsus & Other dytiscids & Physa acuta & Physa acuta \\
\hline
\end{tabular}

\footnotetext{
${ }^{\mathrm{a}}$ Appendix SI2

${ }^{\mathrm{b}}$ Timms (1993, 1998a, b, 2018)

${ }^{\mathrm{c}}$ Hancock and Timms (2002), Timms (2002)

${ }^{\mathrm{d}}$ Timms (1997a, b, 2001b)

${ }^{\mathrm{e}}$ Timms (2001)
} 
diversity of spinicaudatans (Limnadopsis spp., Paralimnadia queenslandicus, Eocyzicus spp.) experienced in those swamps most flooded in 2020 and also in previous floodings at Far Homestead Black Box swamp and Carters Poplar Box flat when some uncommon species were caught in 2000 and 2011 floodings (e.g. Eoleptestheria sp in 2000 and Cyclestheria nr hislopi in 2011) (Timms, 2009; Schwentner et al., 2013). Otherwise, the trees contribute woody detritus to the wetlands and this enhances species diversity, probably not as a food source, but as secure hiding places. Leaf litter from the trees was observed mainly in dry times and hence is processed terrestrially and does not contribute directly to the aquatic system. Hydrological period is also a contributor to diversity in these swamps and flats (Table 2); this is a common ecological driver in dryland wetlands (e.g. Florencio et al. 2011; Timms and Boulton 2001; Davis et al. 2018).

In a more comprehensive study of freshwater aquatic habitats across the Australian arid and semiarid zones but excluding any sites in the Murray Darling basin, Davis et al. (2018) noted 10 types of habitats and major ecological drivers of latitude, connectivity, hydroperiod and biogeographic history, i.e. relic fauna in some isolated sites. Each of the drivers varied in importance with habitat type: latitude applied to most, connectivity to the riverine systems and isolation to desert rockholes, some waters were permanent and hydrologically stable, others temporary and variable. These authors did not look at the influence of water chemistry or related parameters, but had they done so, then (a) salinity as an ecological driver would have featured, as it does in the Paroo, (b) turbidity featured only for the uncommon claypan sites across the arid inland whereas in the Paroo these are common and there are minor variations in water clarity in other Paroo habitat types, and (c) hydrological variability is arguably the most important driver everywhere.

The factor of hydrological variability is shared with Mediterranean wetlands, though in these there is seasonal reliability (Boix et al. 2016), important for at least some niche separation of species, and hence increased diversity. Perceived diversity in the Paroo is artificially low because some groups have hardly been studied (rotifers) or have probably been incompletely collected (e.g. chironomids). However, this is not enough to account for the lower species richness in the
Paroo treed pools when compared to the generally speciose Mediterranean pools or the temporary wetland ponds of temperate regions-gamma diversity > 100 species (Boix et al. 2016; Lake et al. 1989; Pinder et al. 2004; Jeffries et al. 2016). The reason is probably largely due to the unreliable filling of the semiarid Paroo treed swamps, but short hydroperiods and simpler habitat structure may contribute (Florencio et al. 2014a, b). These factors probably also contribute to the lack of any detailed seasonal succession, except those determined by phylogenetic characteristics (e.g. branchiopods early in succession, predatory insects including odonatans maturing late).

Treed swamps also occur in the wheatbelt of Western Australia, including Southern Yate (Eucalyptus occidentalis) and Melaleuca spp. swamps. Such sites generally have abundant vegetation of sedges and a greater diversity of invertebrate assemblages (Pinder et al. 2004) but fewer branchiopods (author unpublished data) compared with Paroo treed swamps. Gross differences could be explained by lower vegetation density and greater environmental harshness of the Paroo treed swamps. Phenological sequences in the Western Australian swamps have not been explored.

The most similar study of a treed swamp in a semiarid climate is by Lahr et al. (1999) of a sahelian temporary pond in Senegal. It had an eight-month hydroperiod and similar fluctuations over time in conductivity, turbidity and $\mathrm{pH}$ as in Paroo treed swamps. Its fauna was dominated early by crustaceans, mainly branchiopods, then later by insects, particularly hemipterans and dytiscids, but with some specific separation in abundances perhaps explained by its longer hydroperiod. Striking similarities include the early dominance of the zooplankter Moina, the early abundance of two species of Anostraca, and the later dominance of the insects Micronecta and Anisops and Eretes. Significant differences include the variety of clam shrimps and ostracods in the Paroo sites in keeping with their high diversity in inland Australia (Schwentner et al. 2015; De Deckker 1983; Halse and Martens 2019), and the greater importance of some lesser insect groups (odonatans, ephemeropterans and trichopterans) in Paroo sites.

Perhaps the greatest unknown of these treed swamps is the ecological role of the trees which define them. So far it seems they are a collateral presence only contributing during super full phases, 
and then only to minor extent. Nutrient flows have not been studied, but where they have in nearby claypans, nutrients were maximal when first full and then soon become depleted (Hancock and Timms 2002). If similar in these treed swamps, such changes would account for the abundance of branchiopods in the first flush and the general scarcity of insects later on. Maybe a nutrient problem could contribute via the paucity of invertebrates, except initially, and of plants to the limited use of waterbirds of treed swamps, compared to their abundance in the saline lakes (Kingsford 1999). Given the abundance of wetlands in the middle Paroo (Kingsford 1999) and hence possibilities for species exchanges, dispersal of branchiopods and insects to these wetlands does not seem to be a problem to rebuild invertebrate populations on re-flooding, thus providing a future comparative study where dryland wetlands are scarce.

\section{Management}

These treed swamps are unmanaged on Bloodwood, Tredega and Muella as elsewhere in the Paroo, though some larger Black Box swamps have long been much modified ecologically by the excavation of dams in them. Many decades of sheep grazing are believed not to have affected the wetlands as sheep keep out water, but same cannot be said for more recent cattle grazing as cattle pug the wet surfaces. The ecological effect of this is unknown, but thought to be minor.

Climate change predictions for the next few decades for the eastern inland of Australia suggest an increase of temperatures by a few degrees, and, though a 10-20\% decrease in annual rainfall, an increase in intensity of summer rainfalls and their unreliability (CSIRO 2021; Huang et al. 2017; IPCC 2014). Neither should influence the robust aquatic fauna of the Paroo. Experiments by Sives (pers. com.) in the hatching of branchiopod eggs from some Paroo wetlands found little change with increased temperatures and the aquatic faunas already successfully deal with the unreliable rainfall. It is possible, however, that seasonal changes in fauna may change with insects more common in winter than they are now (Timms 2018). Given the present rarity of water still present in the treed swamps in winter, response to increase in winter temperatures would be minor. What is already seen, however, is some tropical taxa, such as
Cyclestheria moving southwards (Schwentner et al. 2013). Maybe a few other tropical anostracans and spinicaudatans will also move south. Huang et al 2017

Acknowledgements I am indebted to the Hansons of Bloodwood and the Batys of Muella and Tredega for access to their properties and for various other kind logistic help over the years, also to David Leigo of Dungarvon and Allan McGrath of Booroora for long term rainfall records. I thank Jason Morton for assistance with multivariate analysis, Stuart Halse for the identification of ostracods, Russ Shiel for identification of many cladocerans, cyclopoids and rotifers, and Adrian Pinder and Joan Powling for constructive criticism of the manuscript.

Funding This work is funded by the author in retirement.

Data availability The detailed datasets generated during this study, besides that reported in the paper and appendices, are available from the author on a reasonable request.

\section{Declarations}

Conflict of interest The author declares that he has have no conflicts of interest.

Ethical approval No ethics approval was necessary to study invertebrates in the jurisdiction of the field sites.

Informed consent As noted in the acknowledgements I had permission from the owners to study the treed swamps on their lands. As a retiree under my own auspices I do not need consent for publication.

\section{References}

Bayly IAEB, Williams WD (1966) Chemical and biological studies on some saline lakes of south-east Australia. Aust J Mar Freshwater Res 17(2):177-228

Boix D et al (2016) Invertebrates of freshwater temporary ponds in mediterranean climates. In: Baxter D, Boix D (eds) Invertebrates in freshwater wetlands. Springer, Switzerland, pp 141-189

BOM (2021) ENSO outlook. www.bom.au/climate/outlook. Accessed 20 July 2021

Bridgman HA, Timms BV (2012) Australia, climate and lakes. In: Bengtsson RW, Fairbridge RW (eds) Encyclopedia of lakes and reservoirs. Springer, Dordrecht, pp 73-81

Clarke KR, Gorley RN (2001) Primer v5: user manual/tutorial. PRIMER-E. Plymouth Marine Laboratory, Plymouth

CSIRO (2021) Future climate. www.csiro.au. Accessed 3 Oct 2021

Cunningham GM et al (1981) Plants of Western New South Wales. NSW Soil Conservation Service, Sydney

Davis JA et al (1993) Wetlands classification on the basis of water quality and invertebrate community data vol 6 
wetlands of the Swan coastal plain, vol 6. Water Authority of Western Australia, Perth

Davis JA et al (2013) Building the climate resilience of arid zone freshwater biota. National climate change adaptation research facility. Monash University, Melbourne

Davis J, Sim L, Thompson RM, Pinder A, Brim Box J, Murphy MP, Morán-Ordóñez A, Sunnucks P (2018) Patterns and drivers of aquatic invertebrate diversity across an arid biome. Ecogr 41:375-387

De Deckker P (1983) Australian salt lakes and their history, chemistry and biota-a review. Hydrobiologia 105:231-244

Florencio M et al (2009) Inter- and intra-annual variations of macroinvertebrate assemblages are related to the hydroperiod in Mediterranean temporary ponds. Hydrobiologia 634:167-183

Florencio M, Diáz-Paniagua C, Serrano L, Bilton DT (2011) Spatio-temporal nested patterns in macroinvertebrate assemblages across a pond network with a wide hydroperiod range. Oecol 166:460-483

Florencio M et al (2014) The influence of geomorphology on the composition of aquatic flora and fauna within a temporary pond network. Limnetica 33(2):327-340

Florencio $\mathrm{M}$ et al (2014) Biodiversity patterns in a macroinvertebrate community of a temporary pond network. Insect Conserv Divers 7:4-21

Gaffney DO (1975) Rainfall efficiency and evaporation in relation to drought in Australia. Presented to the 46th ANZASS Congress Canberra 1975, Bureau of Meteorology, Melbourne

Goodrick GN (1984) Wetlands of north-western New South Wales. NSW National Parks and Wildlife Service Occasional Paper No. 6, Sydney, Australia

Halse S, Martens K (2019) Four new genera and five new species of 'Heterocypris' from Western Australia (Crustacea, Ostracoda, Cyprinotinae). Eur J Taxon 493:1-35

Hancock MA, Timms BV (2002) Ecology of four turbid claypans during a filling-drying cycle in the Paroo, semi-arid Australia. Hydrobiologia 479:95-107

Hazelton PA, Johnson PO (1973) Land systems series, Yantabulla, sheet SH 55-S, soil conservation service of NSW. Central Mapping Authority, Bathhurst, NSW

Horwitz P et al (2009) Wetland invertebrate richness and endemism on the Swan Coastal Plain, Western Australia. Mar Freshwater Res 60:1006-1020

Huang $\mathrm{J}$ et al (2017) Drylands face potential threat under $2^{\circ} \mathrm{C}$ global warming target. Nat Clim Chang 7(6):417-422. https://doi.org/10.1038/nclimate3275

IPCC (2014) Summary for policymakers, climate change 2014: synthesis report. Contribution of working groups I, II and III to the fifth assessment report of the intergovernmental panel on climate change. IPCC, Geneva

Jeffries MJ et al (2016) Invertebrates in temporary wetland ponds of the temperate biomes. In: Baxter D, Boix D (eds) Invertebrates in freshwater wetlands. Springer, Switzerland, pp 105-139

Kingsford RT (1999) A free-flowing river: the ecology of the Paroo river. NSW National Parks and Wildlife Service, Sydney

Lahr J et al (1999) Phenology of invertebrates living in a sahelian temporary pond. Hydrobiologia 405:189-205
Lake PS, Bayly IAE, Morton DW (1989) The phenology of a temporary pond in western Victoria, Australia, with special reference to invertebrates. Arch Hydrobiol 115(2):171-202

Maher MT (1991) Waterbirds back o' Bourke, an inland perspective on the conservation of waterbirds. Ph D Thesis, University of New England

Meintjes S (1996) Seasonal changes in the invertebrate community of small shallow ephemeral pans at Bain's Vlei, South Africa. Hydrobiologia 317:51-64

Pinder A et al (2004) Aquatic invertebrate assemblages of wetlands and rivers in the wheatbelt region of Western Australia. Rec West Aust Mus Sup 67:7-37

Rogers DC Timms BV (2014) Anostracan (Crustacea: Branchiopoda) zoogeography III Australian bioregions. Zoot 3881:453-487

Schwentner M et al (2013) Cyclestheria hislopi (Crustacea: Branchiopoda): a group of morphologically cryptic species with an origin in the Cretaceous. Mol Phylogeny Evol 66:800-810

Schwentner M et al (2015) Spinicaudata (Branchiopoda: Diplostraca) in Australia's arid zone: unparalleled diversity at regional scales and within water bodies. J Crustac Biol 35(3):366-378

Timms BV (1993) Saline lakes of the Paroo, inland New South Wales, Australia. Hydrobiologia 267:269-280

Timms BV (1997) A study of the wetlands of Currawinya national park. University of Newcastle, Toowoomba

Timms BV (1997b) A comparison between saline and freshwater wetlands on bloodwood station, the Paroo, Australia, with special reference to their use by waterbirds. Int J Salt Lake Res 5:287-313

Timms BV (1998a) Further studies on the saline lakes of the eastern Paroo, New South Wales, Australia. Hydrobiologia $381: 31-42$

Timms BV (1998b) A study of lake Wyara, an episodically filled saline lake in southwest Queensland, Australia. Int J Salt Lake Res 7:113-132

Timms BV (2001) Limnology of the intermittent pools of Bells Creek, Paroo, arid Australia, with special reference to biodiversity of invertebrates and succession. Proc Linnean Soc NSW 123:193-213

Timms BV (2002) Limnology of the claypans of the Paroo, aridzone Australia. Verh Int Ver Limnol 28:130-133

Timms BV (2009) First records of a leptestherid clam shrimp in Australia (Crustacea, Spinicaudata, Leptestheridae, Eoleptestheria). Zookeys 18:1-16

Timms BV (2015) A revised identification guide to the fairy shrimps (Crustacea: Anostraca: Anostracina) of Australia. Mus Vic Sci Rep 19:1-44

Timms BV (2018) On the influence of season and salinity on the phenology of invertebrates in Australian saline lakes, with special reference to those of the Paroo in the semi-arid inland. J Oceanol Limnol 36(6):1907-1918. https://doi. org/10.1007/s00343-018-7308-1

Timms BV, Boulton AJ (2001) Typology of arid-zone floodplain wetlands of the Paroo River (inland Australia) and the influence of water regime, turbidity and salinity on their aquatic invertebrate assemblages. Arch Hydrobiol 153(1):1-27 
Timms BV (2007) The biology of the saline lakes of central and eastern inland of Australia: a review with special reference to their biogeographic affinities. Hydrobiol 576:27-37

Tooth S, McCarthy TS (2007) Wetlands in drylands: geomorphological and sedimentological characteristuics, with emphasis on examples from southern Africa. Prog Phys Geogr 31(1):3-41

Warner RF (1977) Hydrology. In: Jeans DN (ed) Australia a geography volume I the natural environment. Sydney University Press, Sydney, pp 49-79
Williams WD (1985) Biotic adaptations in temporary lentic waters, with special reference to those in semi-arid and arid regions. Hydrobiologia 125:85-110

Publisher's Note Springer Nature remains neutral with regard to jurisdictional claims in published maps and institutional affiliations. 